\title{
Histological margin assessment for breast ductal carcinoma in situ: precision and implications
}

\author{
Brigitte Sigal-Zafrani ${ }^{1}$, Jacqueline S Lewis ${ }^{2}$, Krishna B Clough ${ }^{2}$, Anne Vincent-Salomon ${ }^{1}$, \\ Alain Fourquet ${ }^{3}$, Martine Meunier ${ }^{4}$, Marie-Christine Falcou ${ }^{5}$ and Xavier Sastre-Garau ${ }^{1}$, on \\ behalf of the Institut Curie Breast Study Group
}

${ }^{1}$ Departments of Pathology; ${ }^{2}$ Surgery; ${ }^{3}$ Radiotherapy; ${ }^{4}$ Radiology and ${ }^{5}$ Biostatistics, Institut Curie, 26 rue d'Ulm, 75248 Paris, France

\begin{abstract}
Local recurrence after lumpectomy for ductal carcinoma in situ (DCIS) is a major concern and is related to residual disease in the breast. We studied the predictive value of lumpectomy margins for residual DCIS and compared our results and pathological processing techniques with those published in the literature. Margin status was determined for 89 patients with screen-detected DCIS who had lumpectomy and re-excision, for the presence and extent of residual disease. Margin width was defined as the narrowest distance between tumor and any inked margin or, where margins were positive, classified into focal involvement $(<1 \mathrm{~mm}$ of the inked surface involved), minimal $(\geq 1<15 \mathrm{~mm})$ and extensive $(\geq 15 \mathrm{~mm})$. The amount of residual tumor was quantified according to the number of ducts involved with tumor: small (fewer than 10 ducts) or large (10 or more ducts) residuum. The initial margin status was a significant predictor for the presence of residual tumor in re-excision specimens $(P=0.006)$. There was residual tumor in 44 and $45 \%$ of close non-involved ( $>1$ and $\leq 1 \mathrm{~mm}$ width) margins, $67 \%$ of focally, $71 \%$ of moderately and $94 \%$ of extensively positive margins. The pathologic tumor size was also a predictor for the presence of residual tumor with 27,68 and $74 \%$ of lesions measuring $\leq 10,11-25$, $>25 \mathrm{~mm}$,respectively, showing residual disease. The presence of residual tumor was not significantly related to age, mammographic appearance, nuclear grade or intraductal necrosis. The initial margin status was found to predict for the amount of residual tumor. With careful margin assessment, margin status after lumpectomy for DCIS can be used to predict for the presence and amount of residual tumor in the breast and is a guide to further management decisions. A standard for margin status reporting and pathological processing of screen-detected DCIS in situ lesions will help in the interpretation of data from different institutions.
\end{abstract}

Modern Pathology (2004) 17, 81-88, advance online publication, 5 December 2003; doi:10.1038/modpathol.3800019

Keywords: ductal carcinoma in situ; lumpectomy; margin; residual disease; histopathology; classification

With the widespread use of mammographic screening for breast cancer, more cases of ductal carcinoma in situ (DCIS) are being detected. Between 1983 and 1992 , there was a $500 \%$ increase in the prevalence of diagnosis of DCIS. ${ }^{1}$ DCIS now accounts for over $14 \%$ of breast cancers diagnosed annually in the United States. ${ }^{2}$

Treatment options for patients with DCIS and DCIS associated with microinvasion have moved from mastectomy to breast-conserving surgery, as conservation of the breast for DCIS allows comparable survival rates with mastectomy. ${ }^{3-5}$ Local recur-

Correspondence: B Sigal-Zafrani, Department of Pathology, Institut Curie, 26 rue d'Ulm, 75248 Paris, France.

E-mail: brigitte.sigal-zafrani@curie.net

Received 12 May 2003; revised 02 July 2003; accepted 18 August 2003; published online 5 December 2003 rences for DCIS are of major concern as half of these are invasive cancers that could impair survival ${ }^{4,6-11}$ Achieving a low recurrence rate is therefore a major goal.

One of the potential predictors for local recurrence in DCIS is the margin status of the excised specimen..$^{5,10,12-18}$ It is therefore a major determinant for further treatment decisions in breast-conserving surgery for DCIS as it is the only factor that can be influenced by physician intervention. The real issue, however, is the presence of residual disease in the remaining breast. The aim of this retrospective study was to assess histologically the margins of initial biopsy specimens for patients with screen-detected DCIS or DCIS with microinvasion and to study the correlation between margin status with the presence and amount of residual tumor in re-excision specimens. Our results and 
Margin status for DCIS

pathological processing methods were compared with those published in the literature.

\section{Materials and methods}

\section{Patients}

Between January 1995 and December 1999, 178 patients with screen-detected DCIS or DCIS with microinvasion had wide excision followed by a reexcision procedure performed at the Institut Curie. Re-excision was performed because the margins of the initial specimen were involved or close (tumor present less than $2 \mathrm{~mm}$ from the inked margin). Out of these 178 cases, a group of 89 patients with unifocal disease estimated to measure less than $3 \mathrm{~cm}$ on mammography was selected to form the basis of this study.

\section{Initial Surgical Procedure}

All lesions were excised following preoperative localization. Wide excision was performed under general anesthesia with the aim of complete removal of the area of microcalcifications and/or mass. Specimen radiography was performed peroperatively to verify that the mammographic abnormality was excised. The surgeon oriented all specimens with sutures and surgical clips. When the lesion was close to the margins on specimen radiography, an immediate complementary excision was performed and oriented. Postoperative mammograms were performed in cases of microcalcifications to verify that the radiographic abnormality was completely excised.

\section{Histopathological Analysis}

\section{Initial excision specimens}

Specimens were inked by the pathologist to allow assessment of the margins and processed using standard institutional methods. Specimens were fixed and serially sectioned in their entirety, in numbered slices every $2-3 \mathrm{~mm}$. Each slice was put in as many numbered separate cassettes as necessary and embedded in paraffin. The median number of blocks was 13 (range: 3-47). Each block was examined on one HES (hematoxylin-eosin-safran)stained slide. Where there was suspicion of microinvasion, the blocks were examined on multiple levels. Microinvasion was defined as the presence of foci of invasive cells measuring less than $1 \mathrm{~mm} .{ }^{19} \mathrm{In}$ this study, only cases with up to two foci of invasion were included. The histological grade of DCIS was evaluated according to the European classification. ${ }^{20}$ The presence and amount of necrosis was recorded. The estimated pathologic size was calculated by multiplying the number of blocks (slides) with tumor by the thickness of the block ( $3 \mathrm{~mm}$ was used as a rule). The distance used to define the margin

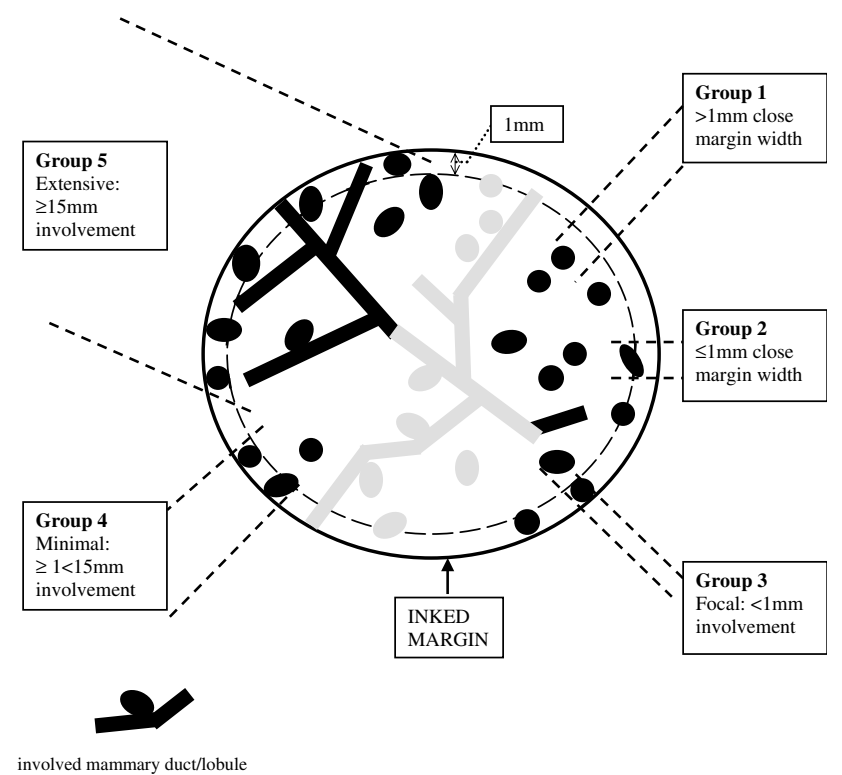

Figure 1 Schematic diagram showing margin status classification of initial lumpectomy specimen: subgrouped according to margin width (clear margin) or extent of margin positivity (involved margin).

width was the narrowest distance between the tumor and any inked margin. In case of an immediate complementary excision, the margin of the second specimen was considered as the final margin.

The population was subdivided into five groups according to the margin width and, in case of margin involvement, to the extent of margin positivity of the surgical specimen (Figure 1):

Group 1: Close margin width $>1 \mathrm{~mm}$, that is, tumor cells present $>1 \mathrm{~mm}$ from the inked surface.

Group 2: Close margin width $\leq 1 \mathrm{~mm}$, that is, tumor cells present $\leq 1 \mathrm{~mm}$ from, but not involving the inked surface.

Group 3: Focal involvement, that is, $<1 \mathrm{~mm}$ of the inked surface involved with tumor (positive margin $<1 \mathrm{~mm}$ involvement).

Group 4: Minimal involvement, that is, $\geq 1<15 \mathrm{~mm}$ of the inked surface involved with tumor (positive margin $\geq 1<15 \mathrm{~mm}$ involvement).

Group 5: Extensive involvement, that is, $\geq 15 \mathrm{~mm}$ of the inked surface involved with tumor (positive margin $\geq 15 \mathrm{~mm}$ involvement).

\section{Re-excision Specimens}

Re-excision procedures were either wide re-excision or mastectomy. A conservative surgical procedure was performed when feasible, that is, when a wide re-excision could be performed without leaving a major deformity of the breast. If not, it was recommended that the patient have a mastectomy.

The extent of tissue sectioning was different for the two types of re-excision procedures. Wide 
re-excision specimens underwent total serial embedding, whereas mastectomy specimens were sampled in 10-15 blocks directed to the primary surgical bed. In addition, the nipple-areolar complex was sampled with three blocks. All specimens were examined for the presence of residual tumor. The size of residual DCIS could not be measured in mastectomy specimens, due to the sampling process (no serial embedding). Therefore, the amount of residuum was quantified according to the number of ducts involved with tumor: small residuum (fewer than 10 mammary ductal/lobular spaces) or large residuum (10 or more spaces) for both types of reexcision specimens. Residual disease was further classified according to histological type: DCIS, DCIS with microinvasion or invasive carcinoma. One pathologist (BSZ) reviewed all slides.

\section{Statistical Analysis}

Clinical and mammographic data were collected from the Institut Curie breast tumor database. Univariate data analysis was performed using Pearson's $\chi^{2}$ test. The likelihood ratio test or Fisher's exact test was used for small numbers. All results with a value of $P<0.05$ were considered to be significant.

\section{Results}

The age distribution of the study group was 37-78 years (mean 54.5), with $18 \%$ of the women aged 45 years or less. The clinical characteristics of the group and the histopathological features of the initial biopsy specimen are shown in Table 1 . Mammography showed microcalcifications in 82 $(92 \%)$ patients, including eight $(9 \%)$ cases where microcalcifications were associated with a mass, and an isolated mass in seven $(8 \%)$ cases. The median pathological size was $25 \mathrm{~mm}$ (range 2-90). Histological examination of the initial specimen margins showed uninvolved margins in 31 (35\%) and positive margins in $58(65 \%)$ cases. The distribution of cases according to margin status was: close margin width of $>1 \mathrm{~mm}$ in nine $(10 \%)$ cases, close margin width of $\leq 1 \mathrm{~mm}$ in $22(25 \%)$, focal involvement in nine $(10 \%)$, minimal involvement in $31(35 \%)$ and extensive involvement in 18 $(20 \%)$.

In all, $46(52 \%)$ patients underwent a breastconserving re-excision and $43(48 \%)$ had a mastectomy as the re-excision procedure. Residual disease was found in $59(66 \%)$ patients. Table 2 shows the relation between the margin status of the initial biopsy specimen and the presence of residual tumor in the same breast quadrant. The presence of residual tumor in re-excision specimens correlated strongly with initial margin status. In all, 44 and $45 \%$ of specimens with close noninvolved ( $>1$ and $\leq 1 \mathrm{~mm}$ width) margins, and $67,71,94 \%$ with positive margin $<1 \mathrm{~mm}$, positive margin $\geq 1<15 \mathrm{~mm}$, positive margin $\geq 15 \mathrm{~mm}$ specimens,
Table 1 Clinical and pathologic characteristics of evaluated cases

\begin{tabular}{|c|c|c|}
\hline Characteristic & No. of patients & $(\%)$ \\
\hline \multicolumn{3}{|l|}{ Age (years) } \\
\hline$\leq 45$ & 16 & (18) \\
\hline$>45$ & 73 & (82) \\
\hline \multicolumn{3}{|l|}{ Mammographic appearance } \\
\hline Microcalcifications & 74 & (83) \\
\hline Microcalcifications with mass & 8 & (9) \\
\hline Mass & 7 & $(8)$ \\
\hline \multicolumn{3}{|l|}{ Mammographic size $(\mathrm{mm})^{\mathrm{a}}$} \\
\hline $0-10$ & 26 & (33) \\
\hline $11-25$ & 36 & (45) \\
\hline$>25$ & 18 & (22) \\
\hline \multicolumn{3}{|l|}{ Pathologic type } \\
\hline DCIS & 74 & (83) \\
\hline DCIS and microinvasion & 15 & (17) \\
\hline \multicolumn{3}{|l|}{ Nuclear grade } \\
\hline Low & 11 & (12) \\
\hline Intermediate & 42 & (47) \\
\hline High & 36 & (41) \\
\hline \multicolumn{3}{|l|}{ Intraductal necrosis } \\
\hline Absent & 13 & (15) \\
\hline Scant & 27 & (31) \\
\hline Moderate/extensive & 48 & (54) \\
\hline \multicolumn{3}{|l|}{ Histological microcalcifications $\mathrm{s}^{\mathrm{a}}$} \\
\hline Present & 79 & (90) \\
\hline Absent & 9 & (10) \\
\hline \multicolumn{3}{|l|}{ Pathologic size (mm) } \\
\hline $0-10$ & 11 & (12) \\
\hline $11-25$ & 28 & (32) \\
\hline$>25$ & 50 & (56) \\
\hline \multicolumn{3}{|l|}{ Margins } \\
\hline Close $>1 \mathrm{~mm}$ margin width & 9 & (10) \\
\hline Close $\leq 1 \mathrm{~mm}$ margin width & 22 & (25) \\
\hline Positive $<1 \mathrm{~mm}$ focal involvement & 9 & (10) \\
\hline Positive $1<15 \mathrm{~mm}$ minimal involvement & 31 & (35) \\
\hline Positive $\geq 15 \mathrm{~mm}$ extensive involvement & 18 & (20) \\
\hline
\end{tabular}

${ }^{\mathrm{a}}$ Missing data.

respectively, had residual tumor in the re-excision specimen $(P=0.006)$. The pathologic size of the tumor did predict for the presence of residual tumor in that $27 \%$ of the lesions $10 \mathrm{~mm}$ or smaller showed residual tumor, compared to 68 and $74 \%$ where the lesions were larger than 10 and $25 \mathrm{~mm}$, respectively $(P=0.02)$.

Totally, 27 (47\%) patients with residual tumor had fewer than 10 ducts involved (small amount of residual disease), whereas 31 (53\%) patients had more than 10 ducts involved (large amount of residual disease). The initial margin status was also a predictor for the amount $(P=0.009)$ of residual tumor (Table 3). A large amount of residual DCIS was found in $48 \%$ of cases with minimally or extensively involved margins as compared with $20 \%$ of the cases with non- or focally involved margins.

Patients with non- or focally involved margins had residual tumor in $50 \%$ of re-excisions, with 30 and $20 \%$ having small and large amounts, respectively. In contrast, cases with minimally or extensively involved margins had residual tumor in $79 \%$ of re-excisions, with 31 and $48 \%$ having small and large amounts, respectively. Overall, 79\% of tumors 
with minimal or extensive margin involvement had residual tumor as compared with $50 \%$ with close margins or focal margin involvement.

Table 2 Probability of finding residual tumor in the re-excision specimen as a function of patient age, margin status, mammographic appearance, tumor size, nuclear grade, presence of necrosis and histological microcalcifications

\begin{tabular}{|c|c|c|c|}
\hline Variable & $\begin{array}{l}\text { Residual } \\
\text { tumor }\end{array}$ & $(\%)$ & $\mathrm{P}$-value ${ }^{\mathrm{a}}$ \\
\hline \multicolumn{4}{|l|}{ Age (years) } \\
\hline$<45$ & $8 / 16$ & (50) & $0.2 \mathrm{NS}$ \\
\hline$\geq 45$ & $51 / 73$ & (70) & \\
\hline \multicolumn{4}{|l|}{ Margin status } \\
\hline Close $>1 \mathrm{~mm}$ width & $4 / 9$ & $(44)$ & 0.006 \\
\hline Close $\leq 1 \mathrm{~mm}$ width & $10 / 22$ & (45) & \\
\hline Positive $<1 \mathrm{~mm}$ focal & $6 / 9$ & (67) & \\
\hline \multicolumn{4}{|l|}{ involvement } \\
\hline Positive $\geq 1<15 \mathrm{~mm}$ minimal & $22 / 31$ & $(71)$ & \\
\hline $\begin{array}{l}\text { Positive } \geq 15 \mathrm{~mm} \text { extensive } \\
\text { involvement }\end{array}$ & $17 / 18$ & $(94)$ & \\
\hline \multicolumn{3}{|l|}{ Mammographic appearance } & $0.8 \mathrm{NS}$ \\
\hline Microcalcifications & $48 / 74$ & $(65)$ & \\
\hline Microcalcifications with mass & $6 / 8$ & (75) & \\
\hline Mass & $5 / 7$ & (71) & \\
\hline \multicolumn{3}{|l|}{$\begin{array}{l}\text { Mammographic tumor size } \\
(\mathrm{mm})^{\mathrm{b}}\end{array}$} & $0.2 \mathrm{NS}$ \\
\hline $0-10$ & $16 / 26$ & $(62)$ & \\
\hline $11-25$ & $22 / 36$ & (61) & \\
\hline$>25$ & $15 / 18$ & (83) & \\
\hline Pathologic tumor size $(\mathrm{mm})^{\mathrm{c}}$ & & & 0.02 \\
\hline $0-10$ & $3 / 11$ & (27) & \\
\hline $11-25$ & $19 / 28$ & (68) & \\
\hline$>25$ & $28 / 38$ & $(74)$ & \\
\hline \multicolumn{3}{|l|}{ Nuclear grade } & $0.9 \mathrm{NS}$ \\
\hline Low & $7 / 11$ & $(64)$ & \\
\hline Intermediate & $27 / 42$ & (64) & \\
\hline High & $25 / 36$ & (69) & \\
\hline \multicolumn{3}{|l|}{ Intraductal necrosis } & $0.6 \mathrm{NS}$ \\
\hline Absent & $7 / 14$ & (50) & \\
\hline Scant & $18 / 27$ & (67) & \\
\hline Moderate/extensive & $33 / 48$ & (69) & \\
\hline \multicolumn{4}{|l|}{ Histological microcalcifications ${ }^{\mathrm{b}}$} \\
\hline Present & $51 / 79$ & (65) & $0.7 \mathrm{NS}$ \\
\hline Absent & $7 / 9$ & (78) & \\
\hline
\end{tabular}

${ }^{\mathrm{a}}$ Refers to distribution of cases. ${ }^{\mathrm{b}}$ Missing data.

${ }^{\mathrm{C}}$ Pathologic size not assessable in every case due to fragmented specimens. NS, not significant.
Classification of residual tumor according to histological type showed DCIS alone in 56 (95\%), DCIS with microinvasion in one $(2 \%)$ and DCIS with invasive carcinoma in two $(3 \%)$ cases. The two invasive cancers were found in cases where there was a greater degree of initial margin involvement. The case with microinvasion was found in the group with minimal involvement. Patients with greater involvement of margins were found to be more likely to end up having a mastectomy $(P=0.007$, Table 4). The presence of residual tumor was not significantly related to age, type of mammographic abnormality, mammographic tumor size, histological grade, presence of histological microcalcifications or intraductal necrosis.

Of note was the underestimation by preoperative mammography of the size of some of the lesions. All patients in this series had microcalcifications measuring less than $30 \mathrm{~mm}$ on the mammogram. In all, $50(56 \%)$ cases were found to have an actual tumor size exceeding $30 \mathrm{~mm}$. The presence of a mass as opposed to microcalcifications on the mammogram did not predict for the likelihood of finding residual tumor in the re-excision specimen.

\section{Discussion}

There is still controversy regarding what constitutes optimal management for DCIS. Mastectomy is still performed for this noninvasive breast cancer, as DCIS sometimes extends over a large area of the breast, and because studies have shown that local control rates are better following mastectomy as compared with breast-conserving surgery. ${ }^{3}$ Moreover, some of the recurrences after breast conserving surgery are invasive carcinomas that could have been avoided with a mastectomy. Despite these higher local recurrence rates, however, the overall survival rates after breast-conserving surgery remain similar to those obtained with mastectomy., ${ }^{3,11}$

Breast-conserving surgery followed by radiotherapy has become accepted treatment for DCIS following the results of randomized controlled

Table 3 Amount of residual tumor in relation to initial margin status

Amount of residual tumor

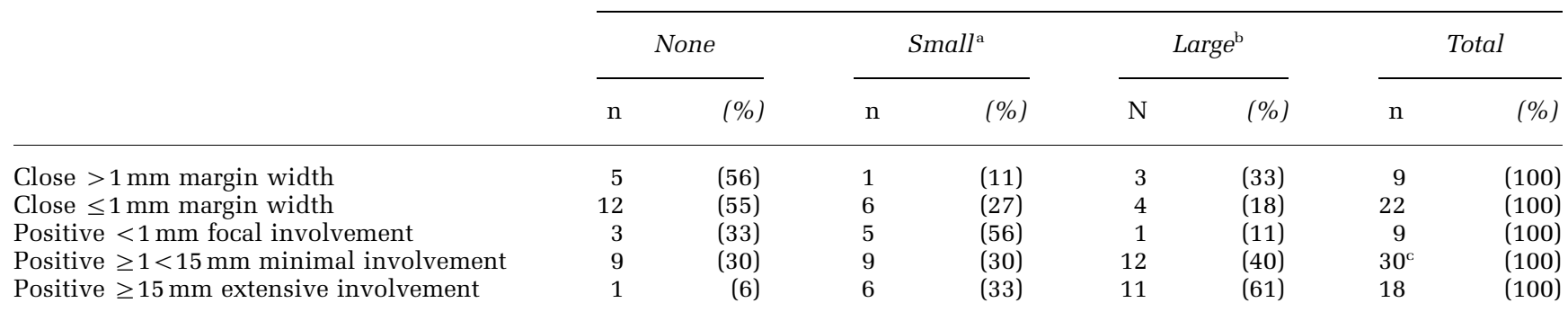

${ }^{\mathrm{a}}(<10$ mammary ductal/lobular spaces involved with tumor.

$\mathrm{b}_{(\geq 10 \text { mammary ductal/lobular spaces involved with tumor. }}$

${ }^{\mathrm{C}}$ Missing data. 
Table 4 Final surgical outcome as a function of margin status of the initial excision biopsy specimen

\begin{tabular}{|c|c|c|c|c|}
\hline & \multicolumn{4}{|c|}{ Surgical outcome } \\
\hline & \multicolumn{2}{|c|}{ Mastectomy } & \multicolumn{2}{|c|}{ Further excision } \\
\hline & $\mathrm{n}$ & $(\%)$ & $\mathrm{N}$ & $(\%)$ \\
\hline Close $>1 \mathrm{~mm}$ close margin width & 0 & $(0)$ & 9 & (20) \\
\hline Close $\leq 1 \mathrm{~mm}$ close margin width & 9 & (21) & 13 & (28) \\
\hline Positive $<1 \mathrm{~mm}$ focal involvement & 4 & (9) & 5 & (11) \\
\hline Positive $\geq 1<15 \mathrm{~mm}$ minimal involvement & 16 & (37) & 15 & $(32)$ \\
\hline Positive $\geq 15 \mathrm{~mm}$ extensive involvement & 14 & (33) & 4 & (9) \\
\hline Total & 43 & $(100)$ & 46 & $(100)$ \\
\hline
\end{tabular}

Table 5 Presence of residual tumor in relation to margin status in various published studies compared with this study

\begin{tabular}{|c|c|}
\hline Margin status & $\begin{array}{c}\text { Residual } \\
\text { tumour (\%) }\end{array}$ \\
\hline \multicolumn{2}{|l|}{ Silverstein et al (31) } \\
\hline Clear: $\geq 1 \mathrm{~mm}$ margin width & 43 \\
\hline Involved: $<1 \mathrm{~mm}$ margin width & 76 \\
\hline \multicolumn{2}{|l|}{ Cheng et al (33) } \\
\hline Positive: tumour at inked margin & 39 \\
\hline Close: $\leq 1 \mathrm{~mm}$ margin width & 19 \\
\hline Negative: $>1 \mathrm{~mm}$ margin width & 14 \\
\hline \multicolumn{2}{|l|}{ Goldstein et al (34) } \\
\hline Negative/close & 45 \\
\hline Unifocal positive $^{\mathrm{a}}$ & 33 \\
\hline Multifocal positive ${ }^{b}$ & 79 \\
\hline \multicolumn{2}{|l|}{ Neuschatz et al (32) } \\
\hline$>2 \mathrm{~mm}$ & 0 \\
\hline$>1-2 \mathrm{~mm}$ & 31 \\
\hline$>0-1 \mathrm{~mm}$ & 41 \\
\hline Focal $^{\mathrm{c}}$ & 30 \\
\hline Minimal $^{\mathrm{d}}$ & 46 \\
\hline Moderate $^{\mathrm{e}}$ & 68 \\
\hline Extensive $^{\mathrm{f}}$ & 85 \\
\hline \multicolumn{2}{|l|}{ Institut Curie (this study) } \\
\hline Close $>1 \mathrm{~mm}$ margin width & 44 \\
\hline Close $\leq 1 \mathrm{~mm}$ margin width & 45 \\
\hline Positive $<1 \mathrm{~mm}$ focal involvement & 67 \\
\hline Positive $\geq 1 \mathrm{~mm}<15 \mathrm{~mm}$ minimal & 71 \\
\hline \multicolumn{2}{|l|}{ involvement } \\
\hline Positive $\geq 15 \mathrm{~mm}$ extensive & 94 \\
\hline involvement & \\
\hline
\end{tabular}

${ }^{\mathrm{a}}$ Margin edge transected a DCIS duct.

${ }^{b}$ Margin transected by $\geq 2$ ducts that was separated by $>5 \mathrm{~mm}$ or a positive margin on $\geq 2$ slides.

${ }^{\mathrm{C}}$ Margin involvement by a single microscopic focus in one histologic section

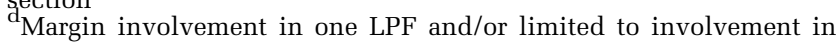
two to four sections at one geographic edge of the specimen.

${ }^{\mathrm{e}}$ Margin involvement in two to four LPFs and/or present in five to șeven sections.

${ }_{\mathrm{f}}$ Margin involvement in five or more LPFs and/or eight or more sections.

clinical trials. ${ }^{4,21}$ Various clinical and pathological factors have been studied that could influence the rate of local recurrence. These have included young age, tumor size, nuclear grade, intraductal necrosis, mammographic appearance, histological presence of calcifications and margin status. ${ }^{5,10,12-18,22-26}$ Results have been inconsistent and various reasons have been cited, including the lack of data with the necessary prolonged follow-up.

As DCIS recurrences occur most often in the same quadrant $^{4,27-29}$ and have similar pathological characteristics to the original tumor, ${ }^{30}$ it has been suggested that they might be related to residual tumor. Various studies have shown that margin involvement is a risk factor for local recurrence. This study was aimed at looking at the rate and amount of residual DCIS after breast-conserving surgery in relation to the margin status and comparing our results and pathological processing methods with that published in the literature. We included cases of microinvasion in this study because local surgical control for DCIS cases with or without microinvasion is identical in this institution.

Our results show that there is a significant correlation between the margin status of the excised specimen and the presence and amount of residual disease after re-excision. These are in keeping with the findings of others who have studied the margin status of re-excision specimens for DCIS ${ }^{31-34}$ (Table 5).

Silverstein et $a l^{31}$ found that when the margin was 'clear' (when all tumor identified was $1 \mathrm{~mm}$ or more from the inked margin) the rate of residual tumor was $43 \%$, whereas when the margin was 'involved' (if the tumor was found less than $1 \mathrm{~mm}$ from the inked margin) there was residual tumor in $76 \%$ (Table 5). Our results show that for cases with an initial clear margin measuring $>1 \mathrm{~mm}$, there was residual disease in $44 \%$ and when the margin width was $\leq 1 \mathrm{~mm}$ or involved, there was residual disease in $70 \%$ of patients. Neuschatz et $a l^{32}$ found that the rate of residual tumor increased when the margin of the initial specimen showed greater tumor involvement, and Goldstein et $a l^{34}$ found that when margins were negative, close or unifocally positive, residual tumor was present in $42 \%$ as opposed to $79 \%$ when margins were multifocally positive. Our results show that when margins are not involved or focally involved, the rate of residual tumor is $50 \%$ and increases to $94 \%$ when there is $\geq 15 \mathrm{~mm}$ of the margin involved with tumor. 
86

In Silverstein et al, Cheng et $a l^{33}$ and Neuschatz et al studies, tumor size was also a significant predictor of whether or not DCIS could be excised with clear margins. Silverstein found residual disease in $57 \%$ of cases for tumors measuring $\leq 24 \mathrm{~mm}$ and in $76 \%$ for tumors $>24 \mathrm{~mm}$. Cheng found residual disease in 30 and $77 \%$, respectively. Our results showed residual disease in 56 and 74\%, respectively. Neuschatz found that the rate of residual tumor increased with increasing tumor size but their results cannot be directly compared with ours, as the quoted size ranges are different. In Goldstein's study, the size of DCIS was not associated with the presence of DCIS on re-excision. These differences in findings may be due to the population selection. In Goldstein's study, the lesion size was not one of the inclusion criteria, whereas our study only included lesions that were estimated to measure $\leq 3 \mathrm{~cm}$ on the mammogram. Another reason may be in the pathological methods used for specimen processing. In our study and that reported by Silverstein, initial biopsy specimens were submitted entirely for histological examination, whereas in Goldstein's study only $50 \%$ were completely embedded.

Differences in pathological methods, that is, differences in the sampling process, could also explain the differences observed between Neuschatz's results and ours. In Neuschatz's study, specimens were not entirely submitted and the blocks were cut with a thickness of $3.0-4.5 \mathrm{~mm}$, with most blocks having a thickness of $3.5-4.0 \mathrm{~mm}$. With these measurements, our definition for minimal margin involvement $(\geq 1<15 \mathrm{~mm}$ involvement of margin by tumor) would be almost comparable to Neuschatz's minimal margin involvement (involvement in two to four sections and/or margin involvement in one low power field). In our study the rate of residual disease was $71 \%$ as opposed to Neuschatz's $42 \%$.

With regard to quantification of residual disease in re-excision specimens, we defined the amounts of residual disease as 'small' (fewer than 10 mammary ductal/lobular spaces involved with tumor) or 'large' (10 or more spaces involved with tumor). This number was chosen arbitrarily. Goldstein recorded the number of slides examined, the number of slides with any DCIS, the maximum specimen dimension and whether the specimen was submitted partially or entirely for pathologic examination. Only $8 \%$ of re-excision specimens were submitted entirely. It seems likely therefore, that for cases of screen-detected DCIS, if the specimen is not embedded in its entirety, and blocks not taken at intervals of $3 \mathrm{~mm}$ or less, it is not possible to obtain an accurate reflection of the amount of residual disease left behind with breast-conserving surgery.

If one accepts that all patients with DCIS who have positive (and/or close) margins need re-excision, then the amount of residual tumor after the initial excision is of little importance, provided that clear margins are obtained. However, our findings that are consistent with other studies show that in some of the re-excision specimens no residual tumor is found. Furthermore, even when tumor is present, the amount of residual disease is often small (fewer than 10 ducts). This is particularly true in cases with close or focally involved margins. The question arises as to whether, in breast-conserving surgery for DCIS, this minimal amount of residual disease can be treated by radiotherapy and therefore further surgery not required. A recent report from our Institute showed that focal margin involvement was not found to be a risk factor for recurrence in a study of 343 patients who received radiotherapy after breast-conserving surgery for DCIS. In that study, however, the dosage of radiotherapy was adapted to the margin status. ${ }^{28}$ An explanation for this could be that the volume of tumor left behind was small enough to be sterilized with radiotherapy. Interestingly, Kestin et $a l^{35}$ showed that close or unifocal/multifocal positive margin status did not significantly predict for local recurrence in their series of patients treated with postoperative irradiation. However, $94 \%$ of their cases received a boost to the tumor bed.

In other studies where margin status has been found to be a risk factor for local recurrence, a reason may be that those cases had a larger degree of margin involvement, which would imply a large amount of tumor residuum. This large volume of tumor may have been too large to be sterilized by adjuvant radiotherapy. An important consideration therefore is the actual volume of tumor left behind and our study gives useful information. When margins are more than focally involved, we found that $31 \%$ have a small amount and $48 \%$ have a large amount of residual tumor.

\section{Conclusions}

DCIS is a three-dimensional lesion, where the margin status is recorded and assessed in a multitude of different ways. We believe that data and recommendations by different workers cannot be adopted without first comparing those differences. With careful pathological assessment of margins, the margin status after excision biopsy for DCIS can be used to predict the amount of residual tumor in the breast and is a guide to further management decisions. This practice may help in increasing the number of cases of DCIS being treated with breastconserving therapy. A standard for reporting margin status and the pathological processing of screendetected DCIS lesions will help in the interpretation of data from different institutions. We have found the classification system used and reported in this study to be simple to use and hope that others will find it easily reproducible. 


\section{Acknowledgements}

Sources of support (grants/equipment/drugs): none.

\section{References}

1 Ernster VL, Barclay J, Kerlikowske K, et al. Incidence of and treatment for ductal carcinoma in situ of the breast. JAMA 1996;275:913-918.

2 Ernster VL, Barclay J, Kerlikowske K, et al. Mortality among women with ductal carcinoma in situ of the breast in the population-based surveillance, epidemiology and end results program. Arch Intern Med 2000;160:953-958.

3 Silverstein MJ, Barth A, Poller DN, et al. Ten-year results comparing mastectomy to excision and radiation therapy for ductal carcinoma in situ of the breast. Eur J Cancer 1995;9:1425-1427.

4 Fisher B, Dignam J, Wolmark N, et al. Lumpectomy and radiation therapy for the treatment of intraductal breast cancer: findings from National Surgical Adjuvant Breast and Bowel Project B-17. J Clin Oncol 1998;16:441-452.

5 Solin LJ, Fourquet A, Vicini FA, et al. Mammographically detected ductal carcinoma in situ of the breast treated with breast-conserving surgery and definitive breast irradiation: long-term outcome and prognostic significance of patient age and margin status. Int J Radiat Oncol Biol Phys 2001;50:991-1002.

6 Price P, Sinnett HD, Gusterson B, et al. Duct carcinoma in situ: predictors of local recurrence and progression in patients treated by surgery alone. Br J Cancer 1990;61:869-872.

7 Solin LJ, Yeh IT, Kurtz J, et al. Ductal carcinoma in situ (intraductal carcinoma) of the breast treated with breast-conserving surgery and definitive irradiation. Correlation of pathologic parameters with outcome of treatment. Cancer 1993;71:2532-2542.

8 Silverstein MJ, Lagios MD, Craig $\mathrm{PH}$, et al. A prognostic index for ductal carcinoma in situ of the breast. Cancer 1996;77:2267-2274.

9 Solin LJ, Kurtz J, Fourquet A, et al. Fifteen-year results of breast-conserving surgery and definitive breast irradiation for the treatment of ductal carcinoma in situ of the breast. J Clin Oncol 1996;14:754-763.

10 Silverstein MJ, Lagios MD, Groshen S, et al. The influence of margin width on local control of ductal carcinoma in situ of the breast. $\mathrm{N}$ Engl J Med 1999;340:1455-1461.

11 Silverstein MJ, Lagios MD, Martino S, et al. Outcome after invasive local recurrence in patients with ductal carcinoma in situ of the breast. J Clin Oncol 1998;16:1367-1373.

12 Bijker N, Peterse JL, Duchateau L, et al. Risk factors for recurrence and metastasis after breast-conserving therapy for ductal carcinoma-in-situ: analysis of European Organization for Research and Treatment of Cancer Trial 10853. J Clin Oncol 2001;19:2263-2271.

13 Fisher ER, Dignam J, Tan-Chiu, et al. Pathologic findings from the National Surgical Adjuvant Breast Project (NSABP) eight-year update of Protocol B-17: intraductal carcinoma. Cancer 1999;86:429-438.

14 Chan KC, Knox WF, Sinha G, et al. Extent of excision margin width required in breast conserving surgery for ductal carcinoma in situ. Cancer 2001;91:9-16.
15 Weng EY, Juillard GJ, Parker RG, et al. Outcomes and factors impacting local recurrence of ductal carcinoma in situ. Cancer 2000;88:1643-1649.

16 Van Zee KJ, Liberman L, Samli B, et al. Long term follow-up of women with ductal carcinoma in situ treated with breast-conserving surgery: the effect of age. Cancer 1999;86:1757-1767.

17 Neuschatz AC, DiPetrillo T, Safaii H, et al. Margin width as a determinant of local control with and without radiation therapy for ductal carcinoma in situ (DCIS) of the breast. Int J Cancer 2001;96:97-104.

18 Vicini FA, Lacerna MD, Goldstein NS, et al. Ductal carcinoma in situ detected in the mammographic era: an analysis of clinical, pathologic, and treatmentrelated factors affecting outcome with breast-conserving therapy. Int J Radiat Oncol Biol Phys 1997;39:627-635.

19 Singletary SE, Allred C, Ashley P, et al. Revision of the American Joint Committee on Cancer staging system for breast cancer. J Clin Oncol 2002;20:3628-3636.

20 Consensus Conference on the classification of ductal carcinoma in situ. The Consensus Conference Committee. Cancer 1997;80:1798-1802.

21 Julien JP, Bijker N, Fentiman IS, et al. Radiotherapy in breast-conserving treatment for ductal carcinoma in situ: first results of the EORTC randomised phase III trial 10853. EORTC Breast Cancer Cooperative Group and EORTC Radiotherapy Group. Lancet 2000;355:528-533.

22 Goldstein NS, Kestin L, Vicini F. Intraductal carcinoma of the breast: pathologic features associated with local recurrence in patients treated with breast-conserving therapy. Am J Surg Pathol 2000;24:1058-1067.

23 Vicini FA, Kestin LL, Goldstein NS, et al. Impact of young age on outcome in patients with ductal carcinoma-in situ treated with breast-conserving therapy. J Clin Oncol 2000;18:296-306.

24 Hetelekidis S, Collins L, Silver B, et al. Predictors of local recurrence following excision alone for ductal carcinoma in situ. Cancer 1999;85:427-431.

25 White J, Levine A, Gustafson G, et al. Outcome and prognostic factors for local recurrence in mammographically detected ductal carcinoma in situ of the breast treated with conservative surgery and radiation therapy. Int J Radiat Oncol Biol Phys 1995;31:791-797.

26 Fisher ER, Costantino J, Fisher B, et al. Pathologic f indings from the National Surgical Adjuvant Breast Project (NSABP) Protocol B-17. Intraductal carcinoma (ductal carcinoma in situ). The National Surgical Adjuvant Breast and Bowel Project Collaborating Investigators. Cancer 1995;75:1310-1319.

27 Schwartz GF, Finkel GC, Garcia JC, et al. Subclinical ductal carcinoma in situ of the breast. Treatment by local excision and surveillance alone. Cancer 1992;70:2468-2474.

28 Fourquet A, Sigal-Zafrani B, Clough KB. Breastconserving surgery plus radiation therapy in DCIS: The Institut Curie experience. In: Silverstein MJ (ed) Ductal carcinoma In Situ of the Breast, 2nd ed. Williams \& Wilkins: Philadelphia, Lippincott, 2002, pp 539-544.

29 Silverstein MJ, Poller DN, Waisman JR, et al. Prognostic classification of breast ductal carcinoma-in-situ. Lancet 1995;345:1154-1157.

30 Bijker N, Peterse JL, Duchateau L, et al. Histological type and marker expression of the primary tumour compared with its local recurrence after breast-conser- 
ving therapy for ductal carcinoma in situ. Br J Cancer 2001;84:539-544.

31 Silverstein MJ, Gierson ED, Colburn WJ, et al. Can intraductal breast carcinoma be excised completely by local excision? Clinical and pathologic predictors. Cancer 1994;73:2985-2989.

32 Neuschatz AC, DiPetrillo T, Steinhoff M, et al. The value of breast lumpectomy margin assessment as a predictor of residual tumor burden in ductal carcinoma in situ of the breast. Cancer 2002;94:1917-1924.

33 Cheng L, Al-Kaisi NK, Gordon NH, et al. Relationship between the size and margin status of ductal carcino- ma in situ of the breast and residual disease. J Natl Cancer Inst 1997;89:1356-1360.

34 Goldstein NS, Kestin L, Vicini F. Pathologic features of initial biopsy specimens associated with residual intraductal carcinoma on reexcision in patients with ductal carcinoma in situ of the breast referred for breast-conserving therapy. Am J Surg Pathol 1999;23:1340-1348.

35 Kestin LL, Goldstein NS, Lacerna MD, et al. Factors associated with local recurrence of mammographically detected ductal carcinoma in situ in patients given breast-conserving therapy. Cancer 2000;88:596-607. 